\title{
Sobre la importancia de investigar en Colombia, un país subdesarrollado
}

\author{
Moisés Wasserman
}

Este breve ensayo es una recopilación de argumentos para sustentar la importancia de hacer investigación científica en Colombia. Está escrito para aquellas personas a las que les concierne el tema en Colombia y en Latinoamérica, que creo debería ser la mayoría de los ciudadanos. Ojalá lo leyeran quienes tienen capacidad decisoria en materia de inversión y en políticas de Estado, aunque temo que ellos generalmente están ocupados con urgencias y, a veces, demasiado convencidos para escuchar argumentos. Para quienes han hecho de la investigación su actividad profesional, los argumentos parecerán ingenuos por lo obvios y autoevidentes. Infortunadamente, no es así para la inmensa mayoría de las personas.

Traté de resumir brevemente los argumentos subyacentes, explícitamente o no, en la apatía con la que es abordado el tema por quienes planifican la actividad nacional y asignan los presupuestos. A continuación, de manera algo apresurada condicionada por la necesaria brevedad del ensayo, traté de rebatir esos argumentos. Lo hice discutiendo las razones por las cuales sí es importante investigar. En primer lugar, los motivos económicos, como el hecho de que la investigación genera riqueza y bienestar, culturas de innovación y competitividad, capacidad para apropiar tecnologías transferidas de otros lugares, y establece una sólida capacidad para la negociación de recursos e ideas. En segundo lugar, los motivos sociales, el papel de la investigación en la construcción de nuestra

Este documento fue preparado para presentarlo en el marco de los Diálogos Globales de la Exposición Hannover 2000.

Correspondencia:

mwasserman@hemagogus.ins.gov.co

Recibido: 06/12/01; aceptado: 02/02/01 salud, de nuestra educación superior y de las estrategias para el control de la calidad de nuestro medio ambiente. En tercer lugar, algunos motivos culturales y políticos, como la necesidad de procesos de toma de decisiones basados en la evidencia y en la racionalidad y de la defensa de una sociedad abierta y democrática ante tendencias autoritarias.

Discuti a continuación, en forma general y sin detenerme en ejemplos y anécdotas, cuál puede ser y ha sido el aporte de la investigación científica en Colombia y, por último, en forma igualmente sucinta, plantée la hipótesis de que a los países desarrollados también les interesa que los subdesarrollados investiguen y generen una capacidad científica significativa que les permita ser auténticos socios e interlocutores en el mundo global que perseguimos.

\section{¿Hay argumentos en contra?}

La afirmación de que vivimos en un mundo globalizado y de que en ese mundo el bien económico fundamental es el conocimiento, ha hecho carrera y se ha establecido en un lugar de honor en la colección de lemas prefabricados de los políticos. Los del primer y los del tercer mundo parecen coincidir en esta apreciación. Sin embargo, sus acciones son fundamentalmente diferentes, como si no respondieran al mismo lema, sino más bien a agendas muy diferentes sustentadas en visiones antagónicas. Así, mientras el mundo desarrollado aumenta su inversión en ciencia y tecnología, construye nuevas instituciones de investigación y educación superior y se hace cada vez más sabio y más competitivo, el tercer mundo limita y reduce sus inversiones en desarrollo científico y en educación, empeora sus estándares y ve, sin que haya muestras de una verdadera preocupación, cómo se amplía su déficit en conocimiento. 
Posiblemente, los problemas económicos sean una explicación para esa desconcertante indiferencia. La necesidad política de mostrar soluciones inmediatas a problemas apremiantes es, con mucha frecuencia, la responsable de que esos problemas dejen de ser coyunturales y se vuelvan estructurales. Sin embargo, creo que detrás de la abulia hay otros argumentos que, generalmente, subyacen esa actitud aunque pocas veces se hacen explícitos, porque para algunos resulta más cómodo y mucho menos comprometedor seguir usando el lema del valor del conocimiento aunque en el fondo no crean en él.

Veo cuatro tipos de argumentos que sustentan, en diferentes círculos de la sociedad, posiciones anticientifistas que son en gran parte el sustento ideológico para la falta de acción. Estos, en forma muy sintética, son los siguientes: 1) No es que los ricos sean ricos porque investigan sino que investigan porque son ricos. La investigación científica es una actividad supracotidiana, tan importante como la ópera pero algo menos que el fútbol, a la cual pueden dedicarse los pueblos que tienen la suerte de tener algo de recursos y tiempo libre.

2) Históricamente, la ciencia colombiana (así como la latinoamericana y la del tercer mundo) no ha producido nada que haya tenido un verdadero impacto en el conocimiento. Es una ciencia apenas imitativa.

3) Económicamente, resulta mucho más conveniente transferir procesos plenamente probados en otras partes que inventar nuevos.

4) La investigación científica es 'punta de lanza' de una cultura occidental que nos trae grandes peligros y que provoca la destrucción de nuestro medio ambiente y de nuestras culturas autóctonas.

Trataré de demostrar en este trabajo que esos argumentos están equivocados y que, por el contrario, existen poderosas razones económicas, sociales, culturales y políticas que sustentan la importancia de la investigación en un país subdesarrollado como Colombia.

\section{Razones económicas a favor}

No es un mito que la ciencia genera riqueza. No es una coincidencia que los países más ricos sean también los que tienen mayor desarrollo científico y mejores universidades. No es un lujo que, a posteriori, se dan los que ya han conseguido todo lo demás. Sería imposible, en un trabajo de las dimensiones de éste, emprender un análisis general de los efectos de la ciencia y de la innovación tecnológica en la economía de los países desarrollados; menos aún podríamos discutir las distintas estrategias que llevaron en cada entorno a que el conocimiento se convirtiera en un factor decisivo de producción, riqueza y bienestar. Sin embargo, creo que es suficiente mirar algunos ejemplos en los que es muy evidente que el desarrollo fue efecto de intervenciones dirigidas a mejorar la capacidad científica y no al contrario. Seguramente algunos de los más notables provienen del sudeste asiático ${ }^{1}$, donde países como Indonesia, Malasia, Singapur, Tailandia y Filipinas han construido una excelente capacidad para generar ciencia como paso previo a una sofisticada industria fuertemente orientada a la exportación. En 1965, hace apenas 35 años, se llevó a cabo en Australia la primera conferencia para promover el desarrollo de la ciencia en esos países que para el momento tenían las economías más pobres de Asia. Sus manufacturas eran menos del $25 \%$ de su producto interno bruto y no llegaban al $6 \%$ de las exportaciones. Después de una época de preparación de sus cuadros en el exterior y del establecimiento de universidades y centros de investigación en las más diversas áreas (que incluian, al lado de algunas muy aplicadas, otras como astrofísica, geología marina y biología molecular) entraron en un dramático crecimiento mantenido durante más de 10 años ${ }^{2}$, que si bien no se puede aducir exclusivamente a la generación de la capacidad científica, no podría ser explicado sin ésta, y que los lleva a tener hoy altísimos índices de productividad. Tal es la relación entre los dos hechos que, ante la reciente crisis económica, 'los tigres del sudeste asiático' (como han llegado a ser conocidos) reaccionaron aumentando sus inversiones en ciencia y tecnología, y no rebajándolas para hacer un ahorro como generalmente hacen nuestros economistas.

\footnotetext{
${ }^{1}$ Science in Southeast Asia. Science 1998;279:1466-82.

${ }^{2}$ World Science Report. London: Unesco Pub.; 1996.
} 
Una muy interesante recopilación de ejemplos en los cuales se correlaciona la implantación de una política de desarrollo científico con un subsecuente desarrollo económico fue objeto de un simposio de la Academia de Ciencias de Nueva York sobre Desarrollo económico basado en ciencia ${ }^{3}$. No sólo estudió casos como los de los 'tigres del sudeste asiático' y algunas iniciativas de países subdesarrollados o en vías de desarrollo, sino casos de estados norteamericanos que con un menor desarrollo tecnológico, como Kansas, Georgia, Oregon, Montana y otros, mejoraron significativamente su productividad, sus ingresos y el perfil de trabajo de sus ciudadanos como consecuencia de una política de fomento a la investigación científica y la educación superior, coordinada con una de fomento industrial.

No es tan extraño este hecho si se piensa que el desarrollo de los Estados Unidos en la primera parte del siglo $X X$ se basó precisamente en sus recursos naturales, en su tierra fértil, en una sociedad abierta y en gente que, sin querer la dependencia del viejo mundo, estaba deseosa de adquirir sus conocimientos. Los primeros científicos americanos se educaron en Göttingen, Oxford, Cambridge y en las mejores universidades europeas y regresaron a los Estados Unidos a aplicar los conocimientos y a construir, al lado del aparato productivo, la más grande empresa de investigación científica y de educación superior en el mundo. A pesar de que durante un buen tiempo esa capacidad de generación de conocimiento estuvo supeditada más a las necesidades del aparato de seguridad nacional que al aparato productivo, es innegable que desde los años 60 el crecimiento económico americano es absolutamente dependiente de su capacidad de innovación.

La afirmación de que la ciencia es motor de desarrollo, es trivial en los países desarrollados ${ }^{4}, y$ nadie en ellos pierde el tiempo sustentando esa

\footnotetext{
${ }^{3}$ Raymond SU, editor. Science-based economic develop ment. Ann New York Acad Sci 1996;798.

${ }^{4}$ En el discurso sobre el Estado de la Unión de 1994, el presidente Clinton decia: "Technology - the engine of economic growth - creates jobs, builds new industries, and improves our standards of living. Science fuels technology's engine."
}

verdad de Perogrullo. Sorprende que no sea igualmente trivial en los países del tercer mundo. No se puede generar algo realmente novedoso si no se ha entrenado la mente en una exploración osada de lo que es posible pero aún no existe. Sólo una educación basada en la investigación científica que, más que dar conocimientos establecidos, proporciona instrumentos analíticos y capacidad para establecer relaciones entre los hechos y para producir hipótesis explicativas y funcionales, puede dar origen a una sociedad que inventa. La riqueza de las naciones en el mundo actual se basa en gran parte en la generación de productos novedosos. No sólo me refiero a artefactos que se vuelven muy rápidamente obsoletos para que otros mejores los reemplacen, sino prácticamente a todos los ámbitos de la vida cotidiana, la alimentación (de muy alta productividad, más nutritiva, más económica, libre de riesgo de plagas), la salud (vacunas, fármacos, sistemas diagnósticos), los materiales que sirven para hacer una mejor raqueta de tenis o un tren más rápido, los sistemas de comunicación y de información.

Se acostumbra decir que los pueblos del tercer mundo tienen mucha inventiva. Creo que hay en esa afirmación mucha verdad y algo de mito y que, infortunadamente, se usa para distraer del hecho de que no es suficiente el ingenio nativo; ese es igualmente abundante en toda la especie humana. Se confunde la verdadera innovación con el ingenio para encontrar remedios locales, baratos, ineficientes y no económicos, a problemas que muy frecuentemente reciben soluciones tecnológicas de fondo, eficientes y económicas en otras partes. Nuestras soluciones son remediales y tienen a veces el encanto de la artesanía y de la anécdota, pero raramente llegan a ser fuentes generadoras de bienestar y prosperidad. Don Miguel de Unamuno hacía un llamado para 'que inventen los ingleses', tratando de resaltar una cierta preponderancia en la capacidad española para las artes y rebajando la importancia del prosaico invento. Efectivamente, los ingleses inventaron (sin que por eso hayan dejado de pintar, escribir o componer). Años después, don Ramón Menéndez Pidal se quejaba de que 'a la carreta de la cultura española le falta 
la rueda de la ciencia', y España se concentró, en un esfuerzo inmenso, para recuperar esa rueda perdida por falta de la cual su carreta social se quedaba rezagada.

Dos aspectos me parece que limitan seriamente la transferencia de tecnología como estrategia independiente de desarrollo (que es una opción defendida por algunos sectores). El primero es que con mucha frecuencia la transferencia de tecnología consiste en la venta de unos equipos y la cesión a cambio de regalías o la venta de un proceso de producción. En este caso, el receptor de la tecnología no podrá ser competidor de quien la transfiere, sino que es un socio subordinado, estará en posición de desventaja competitiva ante cualquier innovación que automáticamente volverá obsoleta la tecnología que adquirió. Requerirá para actualizarla un nuevo contrato de transferencia y una renegociación de los términos. El salto a la independencia y a una auténtica competitividad sólo se logrará cuando él genere la innovación. Es decir, cuando deje de depender de la mera transferencia y comience a depender de su propia y original capacidad científica y tecnológica.

El segundo aspecto que debe tenerse en cuenta, es que una transferencia tecnológica requiere un sustrato propio, una infraestructura de conocimiento mínima para que sea exitosamente apropiada. Son innumerables los ejemplos de compra de tecnología que no puede ser usada en forma eficiente porque no se entiende bien en qué consiste, porque se depende en forma permanente, incluso para el mantenimiento mínimo de equipos, de visitas e insumos del proveedor, porque no se conocen las limitaciones de los procesos y de los productos, y porque cambios pequeños en las condiciones locales producen efectos que, con un pobre conocimiento, no podía prever ni manejar. El receptor de la transferencia en estos casos se convierte simplemente en un agente comercial y la rentabilidad de la producción, su eventual ventaja sobre la importación, dependerá de factores como mano de obra y transporte más baratos. La permanencia de la tecnología transferida en esas condiciones es extremadamente frágil.

Las consideraciones anteriores llevan a la conclusión de que la transferencia tecnológica no es una auténtica opción de desarrollo, sino apenas una estrategia adicional, que sólo será eficiente si existe como base la autosuficiencia que da un desarrollo científico. Cuando éste se dé, el diálogo dejará de ser vertical (de arriba hacia abajo) y se convertirá en un intercambio horizontal en el que la transferencia de ideas se haga entre socios igualitarios y en las dos direcciones, con beneficios amplios para todas las partes.

Un tercer aspecto por considerar se refiere a los recursos naturales que, por sí solos, no constituyen más que una riqueza simbólica. Es muy claro que, si bien son una excelente base para lograr el bienestar, su utilización adecuada depende del conocimiento. Los países con mayores recursos naturales, con la mayor biodiversidad, los más ricos en agua, en minerales y en fuentes de energía no son necesariamente los más prósperos. Hay países pobres en recursos, que le roban centímetros de tierra a los océanos y a los desiertos, pero que son capaces de dar a sus ciudadanos una vida de tranquilidad y abundancia, mientras que países megadiversos soportan unos niveles imposibles de pobreza y de necesidades insatisfechas.

Si se pretende hacer de la diversidad de recursos naturales una fuente de bienestar también es necesario, además de poderla explotar, tener la capacidad de negociarla adecuadamente, y esa capacidad depende fundamentalmente del conocimiento. Puede ser que un funcionario preparado en algo de economía y en relaciones internacionales ni siquiera sospeche las posibles aplicaciones del objeto que negocia (que podría ser aparentemente insignificante como una hoja o una ranita de $2 \mathrm{~cm}$ ) o las implicaciones de la negociación misma. Es tristemente célebre la venta de derechos sobre el bosque húmedo tropical que hizo Costa Rica a la compañía Merck por unos centavos.

Contrastan la composición de las delegaciones de los países desarrollados a las grandes conferencias mundiales para el manejo del medio ambiente y la biodiversidad, con las de los países subdesarrollados dueños de esa biodiversidad. Mientras que los primeros están conformados por equipos de científicos conectados electrónicamente entre ellos y con sus bancos de datos, 
armados de estudios precisos de fotos por satélite y de programas de simulación de impacto, con miles de ideas sobre las potencialidades de bosques, ríos, especies y hasta desiertos, los segundos usualmente están conformados por un ministro o viceministro con un asesor y tal vez una secretaria, armados con algún estudio limitado y de hace un par de años. Si en la reunión se van a tomar decisiones muy importantes tal vez incluyan a un abogado. Del lado del subdesarrollo, el mayor ausente en los foros de negociación y en los círculos de decisión es el conocimiento. Los negocios se hacen con frecuencia cuando una de las partes sufre de una carencia fundamental de ilustración. No hay ámbito en el cual sea más patente que en éste, lo que significa el poder del conocimiento.

José Goldemberg, profesor de física de la Universidad de Saõ Paulo, y en una ocasión Secretario Federal de Ciencia y Tecnología del Brasil, plantea tres campos en los cuales, en su opinión, la ciencia y la tecnología deben jugar un papel en la solución de problemas de los países del subdesarrollo ${ }^{5}:$ 1) contribuir a adaptar la tecnología a las circunstancias locales; su análisis señala la importancia de transferir tecnologías que se demostraron útiles en otros lugares, pero señala que no podrán ser exitosas si no existe la capacidad científica requerida para adaptarlas críticamente; 2) incorporar la ciencia a la educación (discutiré ese punto más adelante), y 3 ) involucrarse en el gobierno, lo que debe entenderse como asumir la responsabilidad de participar en las discusiones y aportar un punto de vista objetivo e ilustrado. Plantea Goldemberg que la ciencia y los científicos deben ser elementos fundamentales en las escogencias y las decisiones de los gobernantes y muestra varios ejemplos personales, entre ellos, su intervención en el diseño de una reserva indígena para los Yanomamis en el Amazonas. Esta aseguró la supervivencia de esa cultura, mientras que el diseño alternativo, impulsado por intereses económicos de corto plazo, prácticamente hubiera asegurado su extinción.

\footnotetext{
${ }^{5}$ Goldemberg J. What is the role of science in developing countries? Science 1998;279:1140-1.
}

A pesar de que no se ha abierto mucho campo en el mundo del subdesarrollo para la participación de la ciencia en la toma de decisiones estratégicas, las pocas ocasiones en que se ha dado la situación, las decisiones han sido mejor tomadas. Ese papel de los científicos es clarísimo en los países desarrollados. Basta observar cómo están compuestos los comités asesores técnicos del congreso norteamericano, donde no es infrecuente ver a premios Nobel discutiendo proyectos de desarrollo. El uso del método científico y de la información y el conocimiento no asegura que se tomen siempre decisiones correctas, pero disminuye apreciablemente el número de grandes equivocaciones.

\section{Razones sociales}

Seguramente uno de los campos más dinámicos de investigación en el mundo es el campo de la salud. Es también un campo donde se han producido avances que afectan a cada persona, disminuyendo sufrimientos y prácticamente duplicando, en apenas un siglo, la expectativa de vida de gran parte de la población humana del mundo. Ese impacto social se ha visto reflejado en una altísima y creciente inversión en investigación en los países desarrollados. Los Institutos Nacionales de Salud son la agencia civil financiadora de investigación más grande de los Estados Unidos ${ }^{6}$; su presupuesto para el año 2000 llegó a ser de más de $\$ 17.000$ millones de dólares y ha venido creciendo en forma constante durante los últimos años. El presidente Clinton aseguró que para el 2002 duplicaría al de 1997.

Seguramente por eso mismo ha hecho carrera en círculos del tercer mundo la teoría de que no vale la pena invertir en investigación en salud, puesto que lo que hay que descubrir será descubierto por los países desarrollados y lo que hay que desarrollar pronto llegará a nosotros distribuido por las compañías farmacéuticas transnacionales. Ese argumento sería válido sólo bajo la premisa de que tenemos los mismos problemas y las mismas prioridades. La premisa no es cierta. Los subdesarrollados hace bastante tiempo que nos morimos de enfermedades distintas. Si bien es cierto que una capa de la población comparte las




preocupaciones de excesos nutricionales que conducen a problemas vasculares, gran parte, por el contrario, sufre más bien de deficiencias nutricionales que disminuyen su capacidad física y mental. Si el cáncer y las enfermedades crónicas de la vejez cobran su cuota de muerte y dolor en los dos mundos, es bien cierto que en el subdesarrollado las enfermedades infecciosas son bastante más importantes ${ }^{7}$.

El enfoque que se le ha dado a algunas de las enfermedades infecciosas en el mundo desarrollado es bastante indicativo del fenómeno que señalo. Estas enfermedades se encuentran bajo la denominación de 'enfermedades emergentes y reemergentes'. Es decir, el acercamiento a ellas desde el mundo desarrollado es el de un peligro que acecha desde afuera y la estrategia para resolverlo es una de estricta vigilancia y control de las fronteras, de alerta ante el caso indicativo para aislarlo y exterminarlo, una estrategia de contención. La imagen que proyectan el cine y las novelas de un científico metido en una especie de traje espacial, cazando virus que entraron de contrabando, es exacta. Para el mundo subdesarrollado no se trata de un problema de contención. Esas enfermedades rara vez son emergentes o reemergentes. Son parte de la vida cotidiana, están en todas partes, tienen sus nichos y reservorios locales. El problema es muy diferente y las soluciones del mundo desarrollado no tienen porqué servirle al subdesarrollado. Sus problemas no se encuentran en los primeros puestos de prioridad de los desarrollados. Sus mercados pobres rara vez justifican grandes empresas de desarrollo para las compañías farmacéuticas.

Otro aspecto importante que sustenta la necesidad de investigación científica para mejorar la salud en el mundo subdesarrollado es que muchas soluciones a problemas de salud pública no requieren de desarrollos novedosos, basta con los instrumentos disponibles. Sin embargo, sí se requiere un conocimiento adecuado de las situaciones particulares, para cada caso y lugar. Ese conocimiento sólo puede ser logrado con investigaciones locales.

\footnotetext{
${ }^{7}$ The World Health Report. Geneva: World Health Organization; 1997.
}

El nivel económico de los pueblos está fuertemente correlacionado con su educación. Si bien se podría aducir, como se planteaba anteriormente con respecto a la inversión en investigación, que son educados porque son ricos, no creo que nadie seriamente conceda alguna validez a esa argumentación. Es indudable que en la medida en que haya gente más idónea a cargo, todos los procesos sociales, productivos y organizacionales, públicos y privados, se llevarán a cabo con mayor eficiencia (Bertrand Russell decía que la eficiencia era una forma excelsa de altruismo). Durante el año de $1998^{8}$ mientras en los Estados Unidos se graduaban 42.215 Ph.D. (155 por millón de habitantes), en China llegaban a 6.042 (5 por millón), y en Colombia (sin datos precisos) no debieron pasar de 10 (máximo 0,25 por millón).

En la universidad moderna, en los sistemas de educación más avanzados, resulta imposible separar la educación superior de la investigación científica. Este hecho ha sido ampliamente sustentado en todo el mundo. Voy a señalar unas pocas razones por las cuales la investigación científica debe ser parte integral en la educación superior en Colombia.

En primera instancia, ya discutimos la necesidad de investigadores y generadores de conocimiento, y resulta obvio que éstos sólo pueden surgir de centros universitarios que hacen investigación y generan conocimiento. Pero la importancia de una educación sustentada en la investigación va más lejos. Los conocimientos que adquiere hoy en día un profesional en casi todas las áreas, tienen una calidad de temporalidad más evidente que nunca en la historia. Si bien tal vez en épocas lejanas un ingeniero, un odontólogo o un contabilista salían de la universidad con la capacidad de actuar con relativa idoneidad durante su vida laboral, hoy en día, el cambio de los instrumentos, los materiales y la tecnología es tan rápido que cualquiera de ellos debe cambiar su bagaje profesional básico varias veces en la vida. El profesional no debe estar preparado como otrora para hacer una tarea, sino para cambiarse a sí mismo al ritmo que cambian sus tareas y los instrumentos con que las ejecuta.

\footnotetext{
${ }^{8}$ Klemm WR. Ph.D. production: a global perspective. The Scientist 2000;14:31.
} 
No me refiero solamente al profesional dedicado a los nuevos desarrollos, sino también al más modesto y menos ambicioso de ellos, pero con una ética que lo impele a hacer las cosas lo mejor posible. Ese tipo de profesional debe ser formado en un medio que valora más la generación de conocimiento y su adquisición por esfuerzo propio, que en un aula repetitiva y memorizante.

Otra razón importante para tener a la investigación como pilar de la educación superior, es la necesidad apremiante que tenemos de líderes capaces de guiar a sus respectivas comunidades en forma inteligente, imaginativa e ilustrada. El mundo desarrollado invierte enormes capitales y esfuerzos en sus universidades emblemáticas. En muchas de ellas, en los mejores programas de investigación y de doctorado, la relación numérica es de 1,5 a 3 estudiantes por profesor ( $y$, iqué profesores!). No lo hacen por mejorar su prestigio, ni por ganar un buen lugar en las tablas de índices de productividad. Esas universidades son verdaderos laboratorios sociales. No son como nuestros laboratorios en los que le 'enseñamos' a los estudiantes técnicas y procedimientos (a veces ni siquiera los más modernos). En esos 'laboratorios sociales', los estudiantes, futuros líderes de la humanidad, están aprendiendo a explorar los límites de lo posible; ellos son los que van a jalonar el desarrollo en los próximos decenios. Necesitamos para nuestro desarrollo líderes como esos, que nos ayuden a comprender el mundo y nuestra posición en él; no nos basta con buenos profesionales.

En todo el mundo, pero muy especialmente en los países megadiversos del trópico como Colombia, ha adquirido alguna importancia una posición 'ecológica fundamentalista' que culpa a la ciencia y a la tecnología por problemas locales como los altos niveles de polución, la extinción de especies y la pérdida de bosques, y por los problemas mundiales como el agujero en la capa de ozono y el calentamiento globa!. Esa posición fundamentalista (que, por supuesto, no es compartida por una parte importante de la comunidad de ecólogos), muchas veces parece dejar como única salida un retorno al pasado, a las épocas y a las culturas en las que el hombre vivía en equilibrio con la naturaleza. Esa posición anticientifista es muy ingenua o muy hipócrita, a menos que se considere sinceramente un regreso a la sociedad de recolectores y de cazadores, caso en el cual tendrían que proponer una solución lo más 'humana' posible para reducir a menos de 500 la población mundial, que llegará en el 2025 a los 8.500 millones de habitantes. Esa es más o menos la población que podría sostener la tierra sin el uso de las tecnologías 'culpables'.

En Colombia, el responsable principal de la deforestación y de la extinción de especies no es la industria de avanzada, ni los cultivos altamente tecnificados, ni todo el progreso occidental, sino la tala indiscriminada de bosques por parte de colonos que buscan su magro sustento en una agricultura primitiva, cuyo principal producto es la hoja de coca.

Quienes señalan con preocupación el agujero en la capa de ozono fueron partícipes de su generación porque usaban desodorantes, tenían como muy natural su nevera y congelador con gases de freón y su luz eléctrica generada en las grandes termoeléctricas. Seguramente ignoraban (como también los científicos) esa consecuencia global de su vida cómoda. Más aún, hoy seguirían sin darse cuenta y continuarian contribuyendo a hacer más grande el agujero, de no ser precisamente por los vilipendiados científicos que descubrieron el fenómeno, definieron sus causas, diseñaron estrategias para controlarlo, inventaron alternativas para reemplazar gran parte de los productos causantes, establecieron sistemas de vigilancia y monitorización y lideraron los movimientos ciudadanos para exigir de los gobiernos desarrollados legislaciones restrictivas y compromisos en el control de sus propias industrias. El problema no está resuelto por supuesto, pero creo que un análisis objetivo llevará a la conclusión de que los instrumentos ofrecidos por la ciencia y la tecnología son la única esperanza de solución. Son esos los instrumentos que la ecología moderna trata de aplicar, infortunadamente, sin contar siempre con el apoyo de todos los sectores involucrados en los gobiernos.

El ejemplo anterior es uno de tantos que sustenta la importancia fundamental de un gran desarrollo científico para poder lograr el ideal del 'desarrollo sostenible' adoptado en 1992 por la comunidad 
mundial en la Conferencia de las Naciones Unidas para el Medio Ambiente y el Desarrollo. Ese lema de 'desarrollo sostenible' significa en forma muy simple que no se deben usar recursos más rápidamente de lo que ellos puedan regenerarse, ni liberar contaminantes en una extensión mayor que la que los recursos naturales puedan asimilar. Si partimos de la premisa honesta de que no podemos regresar a una sociedad en que la expectativa de vida era de 30 años, en la que cada familia producía estrictamente los bienes para su sustento mínimo, y cuando había en el mundo apenas unos cientos de millones de hombres, debemos aceptar que la única forma en que llegaremos al desarrollo sostenible es con mucha tecnología. Tecnología que aumente sustantivamente la producción de alimento por unidad de área y por labriego, que use más eficientemente la energía generada y que use formas de energía que hoy no aprovechamos, que limite las emisiones de gases, que procese residuos y los haga rápidamente biodegradables, que movilice poblaciones más grandes a menor costo energético y con menor emisión de residuos.

En el mundo subdesarrollado tenemos que entender que, si bien la preocupación por el entorno natural es legítima y verdadera, la solución a los problemas ambientales no está en dar un paso atrás sino varios adelante. Los plaguicidas no se eliminarán dejando de usarlos (lo que generaría hambre masiva), sino modificando genéticamente los cultivos para que no los necesiten; las emisiones de los motores no se eliminarán cambiando autobuses por burros, sino diseñando motores eficientes y trampas o catalizadores para eliminar emisiones, o motores que usen energías alternativas; la tala de bosques no se suspenderá sino con agriculturas tecnificadas que no la hagan necesaria.

\section{Razones culturales y políticas}

Es frecuente encontrar en escritos periodísticos y en algunos filosóficos y pseudofilosóficos, la afirmación de que la ciencia occidental es arrogante y autoritaria. Es discutible que sea occidental y es precisamente lo opuesto a arrogante y autoritaria. Pretendo a continuación argumentar que, por el contrario, una razón muy importante para hacer ciencia en el mundo subdesarrollado es precisamente porque ella sirve como un medio de defensa contra los autoritarismos.

No es extraño ver sobre el escritorio de importantes hombres de gobierno (en informes televisados a toda la nación), una pirámide de cuarzo que 'concentra las buenas energías cósmicas' en su dueño y le mejora las posibilidades de éxito en su gestión. En alguna reciente reunión en el exterior, realizada entre representantes del gobierno colombiano y un grupo guerrillero, estalló un escándalo porque los guerrilleros pensaban que estaban siendo espiados con sofisticados equipos electrónicos. No los estaban espiando, les estaban midiendo el 'aura'. Un bien relacionado 'bioenergético' estaba ayudando a diseñar las estrategias de la negociación y para ello le resultaba fundamental conocer el aura de los negociadores del otro bando. Un importante político colombiano afirmaba (con titular de varias columnas en la primera página del periódico de mayor circulación): "aunque no hay pruebas, todo el mundo sabe que la Fiscalía, la Procuraduría y la Defensoría del Pueblo están infiltradas por la guerrilla". ¿Qué extraño mecanismo permite a todo el mundo saber algo sin que exista ninguna prueba?

Esos son algunos ejemplos de nuestra vida política que demuestran la ausencia del método científico en el pensamiento de los dirigentes políticos y en el proceso de toma de decisiones, y esto es muy peligroso. No es casual el hecho histórico de que las oscuras figuras de magos y astrólogos hayan surgido al lado de líderes poco racionales y autoritarios que los necesitan para justificar algunas decisiones.

Cuando la investigación científica está en el sustento educativo de un ciudadano corriente, hay algunos principios mínimos que, aunque no se hayan hecho explícitos, moldearán su comportamiento (si no hace saltos a la irracionalidad). Estos son: 1) todo lo que sé está fundamentado en teorías que han sido contrastadas con la realidad infinidad de veces, pero puedo estar equivocado; debo, por tanto, estar dispuesto a examinar críticamente propuestas nuevas; 2 ) no puedo decir con toda seguridad que 
mi hipótesis es verdadera por una mera confrontación con los hechos, pero sí puedo descartar, por ese medio, las que sean falsas $y$, de esa forma, aproximarme a una interpretación con verdad; 3 ) la retórica no puede suplir un contraste con la realidad; tengo medios para distinguir entre un ejercicio lingüístico y una argumentación real, y 4) mis actitudes en todos los campos de la vida deben ser coherentes con mi actitud hacia el conocimiento, es decir, mis opiniones deben acercarse a la verdad.

No es mi intención entrar en una discusión con tendencias filosóficas modernas (posmodernas) y viejas con nuevos ropajes, que no aceptan estas premisas, sino hacer explícitas algunas de las bases del comportamiento de un ciudadano corriente, con un buen sustento de educación científica (básica, social o humana) y con un sólido sentido común. Creo que la ausencia de esos subproductos de una educación basada en ciencia genera problemas culturales y políticos de enorme gravedad; las tres situaciones auténticas anteriormente descritas son ejemplos de esa deficiencia. El diseño de acciones confiando en energías cósmicas, la construcción de negociaciones basándose en las auras de los contrincantes y una justicia en la que 'todos saben' sin necesidad de pruebas, no pueden conducir a una sociedad mejor.

Los lemas de Feyerabend de que 'la ciencia no es más que otro mito' y que, por tanto, 'todo vale' llevan a una preponderancia de la propuesta retórica del 'discurso' sobre las teorías científicas contrastadas con la realidad. Si la contrastación con la realidad no es necesaria ni deseable, la vigencia de una teoría dependerá de las maromas retóricas o de la fuerza. La historia de la humanidad está llena de ejemplos en los que se comienza con la retórica y se termina con la fuerza. La ciencia y la educación basada en ciencia, son instrumentos invaluables de los pueblos como antídoto contra el autoritarismo.

\section{¿Se ha producido conocimiento científico en Colombia?}

El argumento de que no vale la pena invertir en ciencia en Colombia porque de todas formas nunca se ha producido algo significativo, es particularmente perverso ${ }^{9}$. Es perverso porque se usa para perpetuar la situación que aparentemente está denunciando. Efectivamente, la producción científica es muy costosa. Si se midiera la producción en número de artículos científicos, por ejemplo, en 1996 se produjeron en los Estados Unidos 6,56 por cada millón de dólares invertidos ${ }^{10}$. Eso implica que Colombia, con el presupuesto asignado a Colciencias, única agencia financiadora estatal, debía producir en el 2000 sólo 41 artículos científicos (además, sin tener en cuenta las diferencia de infraestructuras, equipos, bibliotecas y otros). Me atrevo a adivinar que Colombia va a producir algo más que eso. Si se midiera la expectativa de productividad de acuerdo con el número de personas dedicadas a la investigación, no podríamos aspirar a nada más que $0,01 \%$ de la producción científica mundial. En efecto, $94 \%$ de los científicos que trabajan en el mundo lo hacen en los países desarrollados, $1 \%$ en Latinoamérica y apenas un $0,01 \%$ en Colombia ${ }^{11}$. Eso sin considerar el efecto potenciador que tiene una comunidad grande, diversa y bien establecida sobre la productividad. En Colombia, se ha producido lo que se podía en sus circunstancias y no es posible medir la productividad sin tener en cuenta cuáles son los instrumentos que el Estado y el sector privado han dispuesto para ese efecto.

A pesar de lo anterior, y puestos en las proporciones adecuadas, la mínima comunidad científica colombiana ha hecho cosas importantes. Si se conoce algo de nuestra biología, de la distribución de especies de plantas y animales, de la estructura geológica, de la dinámica de nuestras enfermedades e incluso de algunos aspectos de su biología, del clima, de posibles aplicaciones industriales de productos naturales

\footnotetext{
${ }^{9}$ Ese argumento, en más palabras y adicionado con la afirmación de que no existe un Sistema Nacional de Ciencia y Tecnologia, fue sustentado por el entonces jefe del Departamento Nacional de Planeación ante el Senado de la República, cuando se lo citó para que explicara porqué en el plan cuatrienal de desarrollo la inversión en ciencia había sido prácticamente reducida a un pequeño componente de 'apoyo a las exportaciones'.

${ }^{10}$ May RM. The scientific investments of nations. Science 1998;281:49-51.

${ }^{11}$ World Science Report. London: Unesco; 1996.
} 
y de innumerables aspectos de nuestra realidad física, biológica y social, se debe a un discreto y constante trabajo autóctono, hecho generalmente con los niveles de rigor usuales en la comunidad internacional. Esos conocimientos no han sido importados de ningún lado, puesto que no existían ni interesaban a nadie más que a nosotros.

También se ha explorado en campos diversos y no necesariamente relacionados con conocimientos autóctonos. Se ha mirado a las estrellas y medido la distancia que nos separa, por ejemplo, de las Efeidas; se han estudiado nuevos materiales, superconductores, semiconductores, cerámicas, fibras de carbón; se ha participado en la exploración de la composición subatómica de la materia; se ha estudiado la biología molecular de organismos patógenos para nosotros y para otros. En resumen, se ha participado con un aporte modesto pero tan significativo como cualquier otro de tamaño similar, en la construcción conjunta de la más grande empresa de la especie humana en todos los tiempos, su ciencia. Esa participación refleja nuestra responsabilidad en el mundo y es un componente importante de nuestra dignidad como hombres y de nuestra nacionalidad. Así como no se puede dejar de escribir poesía porque todavía hay ciudadanos que no saben leer, no se puede dejar de hacer investigación científica porque hay crisis fiscal. Si queremos tener un papel en el diálogo global, el más natural conducto de interlocución es la ciencia.

\section{¿Para los países desarrollados, es importante la investigación científica en los países subdesarrollados?}

El verdadero desarrollo global no puede darse sin un crecimiento igualmente global en el conocimiento. En 1992, se constituyó en los Estados Unidos la Comisión Carnegie para Ciencia, Tecnología y Gobierno. La comisión, presidida por el ex presidente Jimmy Carter, tenía por objeto hacer aportes conceptuales a la sociedad y al gobierno norteamericanos acerca de las tendencias del desarrollo en el mundo nuevo de la posguerra fría. El informe de la comisión, entre otros, señalaba algunos puntos que tenían que ver con el desarrollo basado en tecnología y las relaciones entre las naciones que voy a resumir a continuación:
"El nuevo orden internacional exige un desarrollo cooperativo global. Durante los pasados doscientos años, las transformaciones sociales y tecnológicas le permitieron a un par de docenas de sociedades llegar a niveles inimaginables de riqueza y bienestar. Sin embargo, durante la década de los 80 se incrementó la competición entre las naciones lo cual llevó a una saturación de mercados y a una inestabilidad económica preocupante. La salida depende en buena parte de que muchas otras sociedades entren a formar parte del exclusivo club de las sociedades ricas. Para lograr ese desarrollo global, es necesaria una transformación social, científica y tecnológica comparable con la revolución industrial.

La única manera de enfrentar ese reto es aumentando sustancialmente las contribuciones de la ciencia y la tecnología al desarrollo, y mejorando la cooperación entre las naciones, que hoy se dividen claramente entre las científicamente ricas y las científicamente pobres. Todos los desarrollos fundamentales esperados en el mundo - crecimiento económico, protección ambiental, mejor salud, mayor productividad agropecuaria y manejo eficiente de las poblaciones - dependen de la capacidad que tengan los países para generar, absorber y usar ciencia y tecnología de vanguardia".

La conclusión de este aspecto en el trabajo de la comisión Carnegie dirige dos mensajes distintos, uno a los países desarrollados y otro a los subdesarrollados, los dos admirables por obvios y claros. A los subdesarrollados les dice que la riqueza, en el siglo que comienza, depende realmente del conocimiento. A los desarrollados les dice que no pueden crecer indefinidamente si ese crecimiento no se acompaña con el de los países más pobres. Observación de Perogrullo; si los dos somos pasajeros del mismo planeta, no podemos avanzar indefinidamente a velocidades tan distintas, porque el terreno que nos une tiene un límite de elasticidad y una ruptura sería catastrófica para todos.

La globalización no es posible entre socios tan exageradamente desiguales. Se necesita mantener una base común de conocimiento para que las tecnologías y los productos del otro sean asimilables. La ausencia de esa base común 
llevará a la ruptura de la comunicación. El mundo global ideal dejaría de ser posible y se generarían necesariamente barreras de contención, no sólo para enfermedades y plagas emergentes, sino para productos, para poblaciones y para culturas. Nadie querría vivir en un mundo así; por eso, el desarrollo científico de las naciones subdesarrolladas es también de interés para las desarrolladas.

La ciencia es el ámbito abierto en el cual se encuentran los dos mundos. Es innegable que el desarrollado recibe con gusto y generosidad a los mejores estudiantes del subdesarrollo para que lleven a cabo sus estudios doctorales e inicien sus carreras de investigadores. En los Estados Unidos, en muchos campos, la mayoría de estudiantes para Ph.D. son extranjeros, y su número se duplicó desde $1995^{12}$. Es innegable también que gran parte de esos estudiantes brillantes se establecen y llevan a cabo sus carreras investigadoras en los países desarrollados que les ofrecen mucho mejores condiciones de trabajo. Si el mundo desarrollado asume la importancia de un crecimiento científico más coordinado con el de los países pobres, debe generar mecanismos decididos de cooperación internacional. Uno de ellos podría hacer uso de las decenas de miles de excelentes embajadores de esos países que son sus estudiantes de doctorado. Pero seguramente la prueba definitiva sería la generación de joint ventures en las que los países más pobres en conocimiento puedan llevar sus ideas desde el estadio más primitivo hasta el de desarrollo industrial, participando en todo el proceso, desde la adquisición básica de información y conocimiento, hasta el desarrollo industrial y comercial, con respeto mutuo de las características particulares en las distintas formas de ver la vida y en hábitats y medio ambiente. Sólo un avance coordinado nos permitirá seguir disfrutando a los dos mundos de este planeta, que, a la larga, es nuestro mayor y más compartido capital.

\section{Epílogo}

El ensayo no trae recomendaciones. Después de dos misiones nacionales e innumerables

${ }^{12}$ Klemm WR. Ph.D. production: a global perspective. The Scientist 2000;14:31. actividades de planeación estratégica en los últimos 10 años, la única recomendación sensata sería que no se hicieran más estudios y que se aplicaran algunas de las recomendaciones que se han dado. Cualquier estrategia que fortalezca y aumente la capacidad para hacer ciencia tendrá un efecto positivo, independientemente de los detalles y de las prioridades adoptadas.

En mi trabajo como profesor de bioquímica trato de que mis estudiantes comprendan las estrategias que se generaron en la naturaleza para hacer posible la vida. El problema central consiste en cómo construir moléculas muy complejas a partir de unas simples, lo que sería termodinámicamente un imposible si no se acoplaran reacciones que liberan energía con las reacciones de 'construcción' que la requieren. La evolución de la naturaleza podía escoger entre dos posibles estrategias generales y las dos se desarrollaron. La primera consiste en acoplar directamente una reacción que genera energía con una que la requiere. La segunda, que ha resultado muchísimo más productiva y poderosa, consiste en tener una gran batería de reacciones que producen energía sin una destinación muy específica. Están reguladas de tal forma que mantienen en la célula viva un alto nivel de energía potencial y ésta sirve para mover todas las otras reacciones.

Esa descripción sacada de la naturaleza, más aún del fundamento mismo de la vida, es una buena analogía sobre las maneras que tenemos de impulsar el desarrollo. Los países menos eficientes tienden a acoplar directamente sus iniciativas de desarrollo científico a programas que responden a necesidades inmediatas y de corto plazo. Se escogen las iniciativas puntuales a través de sistemas de prioridades muy estrechos, generalmente definidos por aquéllo que los administradores imaginan que es rentable desarrollar, y las iniciativas con objetivos más generales (incluidas las de formación de científicos y educación hacia la ciencia) son relegadas. El sistema de fijar prioridades reducidas, con base en consideraciones inmediatistas, en un medio que como el del subdesarrollo tiene más prioridades que científicos disponibles para ocuparse de ellas, tiene grandes peligros. Algunos de ellos pasan por la pérdida de 
presencia en campos que, aunque no lo parecía en un momento, demuestran su importancia a posteriori; la distracción, en pos de 'modas', de esfuerzos que debían estar concentrados en desarrollos fundamentales, y por la migración de científicos de los campos en que son expertos a otros en los cuales son apenas aprendices.

La segunda opción, aquélla que ha sido escogida por los países más desarrollados, es la generación agresiva de una comunidad amplia de investigadores, con objetivos diversos y con una libertad para investigar que sólo está limitada por la calidad y la productividad. Es, en esencia, el mismo sistema ingenioso desarrollado por la evolución, centrado en el mantenimiento de una energía potencial alta, es decir, en una buena capacidad de respuesta inmediata a los retos y problemas que se presenten. Es esa capacidad de respuesta lo que define realmente a una sociedad desarrollada. 